\title{
Spigelian Hernia-Diagnostic Dilemma: Case Report with Review
}

\author{
Sunder Goyal*, Sanjeev Singla \\ Kalpana Chawla Govt Medical College, Karnal, India \\ Email: *goyal.sunder@yahoo.in, sanjeev77@gmail.com
}

Received 12 June 2014; revised 20 July 2014; accepted 26 August 2014

Copyright (C) 2014 by authors and OALib.

This work is licensed under the Creative Commons Attribution International License (CC BY). http://creativecommons.org/licenses/by/4.0/

(c) †) Open Access

\section{Abstract}

Spigelian hernia (SH) is an uncommon surgical entity in children and rare in adults. Due to various reasons, spigelian hernia can develop through defects in transversus abdominis aponeurosis. Usually spigelian hernia develops below the arcuate line of Douglus and rarely occurs at higher level. It poses a diagnostic dilemma for surgeon as there are no specific symptoms and signs. It comprises about $0.12 \%$ of all abdominal wall hernias. The spigelian hernia has been repaired by both conventional and laparoscopic approach. We present a case of spigelian hernia in left half of lower abdomen in a 15-year-old child.

\section{Keywords}

Transversus Abdominis Aponeurosis, Spigelian Hernia, Laparoscopy

Subject Areas: Pediatrics, Surgery \& Surgical Specialties

\section{Introduction}

The word spigelian hernia was derived from the name of Adrian van der Spieghel (1578-1625), who was a practicing surgeon-anatomist-botanist in Padua of Italy. However, in 1764 Klinkosch1 described a spontaneous lateral ventral hernia specifically located in the semilunar line. In 1935, Scopinaro was the first to report a lateral ventral hernia in a pediatric patient. Most of spigelian hernias occur in the lower abdomen where the posterior sheath is deficient. It is also called "spontaneous lateral ventral hernia" or "hernia of semilunar line". The diagnosis of spigelian hernia (SH) is difficult and poses diagnostic challenge to clinician. There is no noticeable mass on inspection or palpation when hernia is interparietal. About 1000 cases of SH have been reported up to 2013. Only 37 cases of SH have been reported in the pediatric age group in a review of the literature from 1935 to 2000 [1]. Although adult spigelian hernias are considered to be acquired because of trauma or increased intra-abdominal pressure, the pediatric cases are suspected to be congenital. Although many case reports have de-

${ }^{*}$ Corresponding author. 
scribed the presence of a variety of abdominal organs in Spigelian hernias, there are no reports of an incarcerated appendix [2]. We report a case of SH in a 15-year-old boy presented with recurrent abdominal pain for the last 6 months.

\section{Case Report}

A 15 yrs male child presented with recurrent abdominal pain with swelling in left lower abdominal area for the last 6 months. Cough impulse was positive and it was a reducible swelling (Figure 1). A clinical diagnosis of spigelian hernia was suspected. Blood investigations, Ultrasonography of whole abdomen, X-ray Chest were done. All reports were within normal limits. Operation was done under epidural anesthesia. A transverse incison over the swelling was made. The sac was exposed which was containing omentum. Omentum was replaced back in abdomen (Figure 2). A space was made out by dissection in extra peritoneal space, deep into the muscle fibers. A proline mesh (6”X4") was placed in extra peritoneal space (Figure 3). Muscle fibers were approximated over it with 2-0 proline. The rest of the operated area closed in layers. Post-operative period was uneventful.

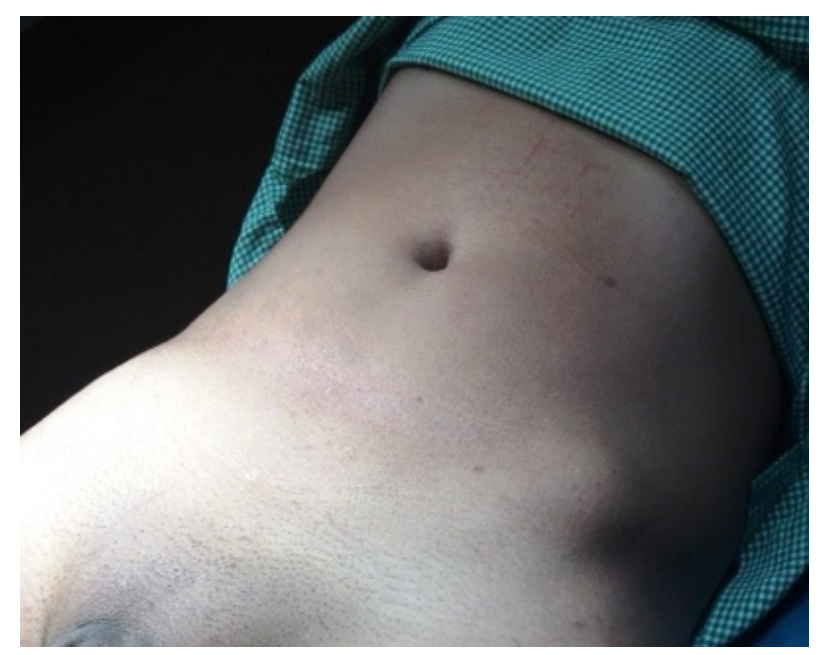

Figure 1. Swelling in left lower abdomen.

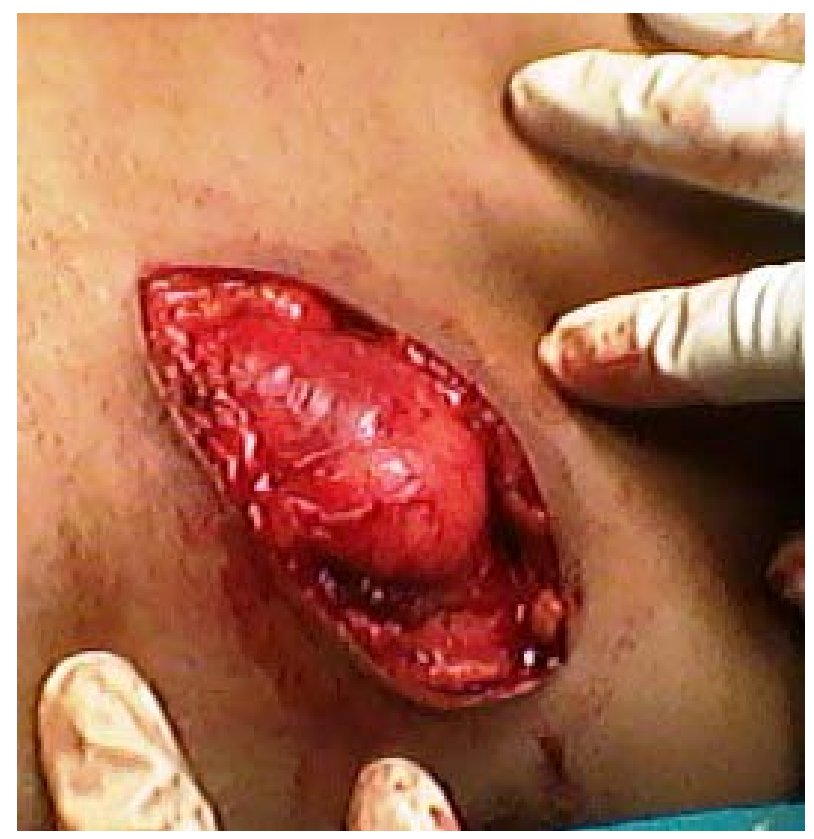

Figure 2. Hernia with omentum in sac. 


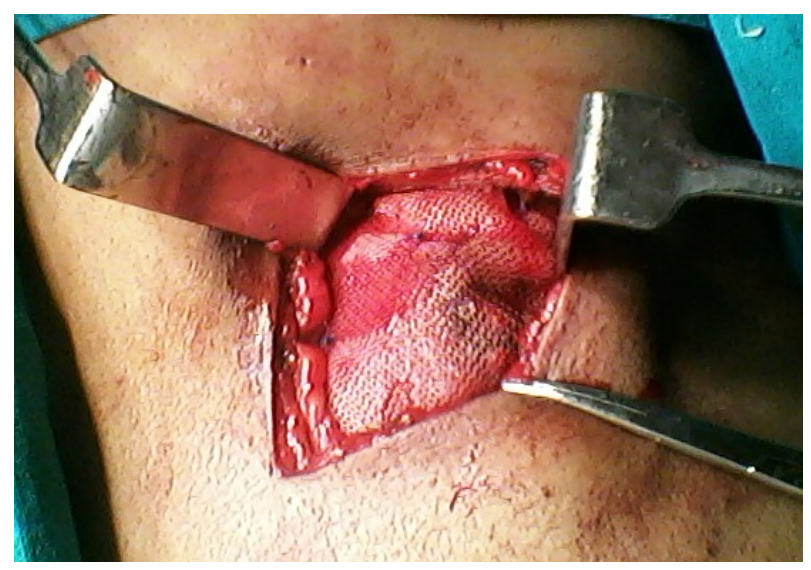

Figure 3. Pre-peritoneal prolene mesh for repair.

\section{Discussion}

The eponym spigelian hernia was derived from the name of Adrian van der Spieghel (1578-1625), who was a practicing surgeon-anatomist-botanist in Padua of Italy. Spigelian fascia is that portion of aponeurosis that extends between semilunar line and lateral border of rectus abdominis. It is widest in a $6 \mathrm{~cm}$ wide portion of abdominal wall above the line joining two anterior superior iliac spines, and it extendes above arcuate line of Douglas. About 85\% - 90\% of the hernias occur within this “spigelian hernia” belt. This region is known as spigelian Belt or Zone. Spigelian fascia in its upper 2/3 rd is reinforced by prolongation of muscular fibres of transversus abdominis. It averts herniation through this area. It is called high spigelian hernia when it occurs in upper half. Spigelian hernias is a relatively uncommon entity with a incidence of $1 \%$ - $2 \%$ among all hernias and only $0.1 \%-0.2 \%$ of abdominal wall hernias [3].

In children, spigelian hernias can occur in all age groupranging from newborn to 17 years of age. They are more frequent in males than females (ratio, 3.7:1). Usually they are on left-side and can be bilaterally in $15 \%$ of cases [1].

In adults, they mostly occur on the right side, between fourth to seventh decades of life. They are more frequent in women (ratio, 4:3) and are rarely bilateral [1].

Spigelian hernia can be congenital or acquired. A small fat enters through weak area in spigelian fascia where perforating vessels enters and gradually leads to hernia formation. Obesity, multiple pregnancies, previous surgery or scarring may result in stretching of abdominal wall and may result in SH.

Eombryologically, weak areas may occur in anterior abdominal wall during development of abdominal muscles as they develop separately in the mesenchyme of the somatopleara [4]. At molecular level, there may be defective elastic fibre synthesis due to deletion of gene 7q1123 [5]. Chances of SH increases due to coexisting gene 2 defect which results in collagen synthesis disorder along with other co-existing genetic disorder syndromes, viz. Williams syndrome. Neonates sometimes may be associated with other type of hernia, cryptorchidism [6] and genetic disorder syndromes [5].

SH may presents as reducible parietal swelling with positive cough impulse. Only $50 \%$ of cases are diagnosed preoperatively. It may present as a swelling adjacent to the iliac crest (as in our case). The patient may have a classic lump when he/she stands up. The lump is painful if the patient stretches and disappears on lying down. It is called "Masked" hernia of Macready when SH presents as a small obscure sac hidden under the layers of abdominal muscles [7]. Spigelian hernias have a real risk of strangulation due to sharp fascial margin around the defect. Richter type of hernia has also been reported to occur with spigelian hernia.

Rectus sheath haematoma, parietal abscess, parietal lipoma, metastatic deposit, cystic changes around lower end of ventriculo peritoneal shunt, appendicitis, appendiceal abscess and a tumor of abdominal wall may resemble with SH [8] [9]. Sometimes the local discomfort can be confused with peptic ulceration. Rarely the hernia can enter the rectus sheath and can be confused with spontaneous rupture of rectus muscle or with a hematoma in the rectus sheath.

Ultrasound is first line imaging diagnostic modality. US should be done in standing as well as in lying down position while the patient carries out Valsalva maneuver. Diagnostic success rate is high with this imaging tech- 
nique. In doubtful cases computed tomography (CT) and magnetic resonance imaging (MRI) are useful in preoperative period [10].

\begin{tabular}{|c|}
\hline Algorithm of Disease \\
Patients present with \\
Lump in iliac fossa \\
Lump may or may not painful \\
Spigelian hernias real risk of strangulation \\
Diagnosis clinical mainly and confirmed with \\
Ultrasound, Computed tomography and Magnetic Resonance Imaging \\
Treatment -Always Surgery \\
Open surgery \\
Laparoscopic technique
\end{tabular}

Surgery is main stay of treatment. Mostly, herniorrhaphy or hernioplasty is done as open surgical procedures.

Various procedures are:

Conventional open surgical approach—A transverse incision is made over the protrusion and external oblique aponeurosis is cut to expose peritoneal sac. Most of the time omentum is content of sac (as in our case). Rarely, intestine, appendix, stomach or ovary can also present in sac. Most surgeons simply invert the sac alone. The hernial orifice can sutured mesh may be placed either in pre-peritoneal space or above the fascia (as in our case).

Laparoscopic Technique: Laparoscopic technique is economical as compared to open surgical technique because hospital stay is less. It is less painful and scar less surgery. Chances of wound infection is minimum with laparoscopic technique First intraabdominal laparoscopic repair of spigelian hernia was carried out by Carter and Mizes in 1992 [11]. Trans peritoneal or extraperitoneal placement of mesh can be done with laparoscopic technique. After that there have been multiple publications of successful management of spigelian hernia by laparoscopy [11]-[14]. In these reports, mesh is placed either intraperitoneally or extraperitoneally after creating a peritoneal flap by trans abdominal approach. In the only prospective randomized controlled trial comparing conventional versus laparoscopic management of spigelian hernia (11 conventional and 11 laparoscopically) there was significant advantage in terms of morbidity and hospital stay in laparoscopy group [15].

Transperitoneal/Extraperitoneal placement of mesh

Transperitoneal approach-Once the hernia sac contents are reduced, a peritoneal flap is raised as in trans abdominal pre peritoneal (TAPP) approach and the hernial sac is reduced completely. After dissecting the peritoneal flap for about $5 \mathrm{~cm}$ around the hernial defect, Prolene mesh is placed in the dissected extraperitoneal space and is fixed using tacks or suture.

Extraperitoneal approach-Endoscopic TEP repair is performed using 3 midline ports. Extraperitoneal space is created by open access and balloon can also be used. The spigelian hernial sac is defined around arcuate line and complete reduction is acquired. The peritoneum is dissected above the arcuate line to have a $5 \mathrm{~cm}$ margin around the hernial defect for mesh placement. A Prolene mesh is used to cover the hernial defect. Mesh is fixed to anterior abdominal wall with spiral tacks or sutures.

The extraperitoneal placement of mesh is better than transperitoneal technique as there isno chances of intestinal obstruction and fistulization of bowel [16] [17]. As compared to transabdominal extraperitoneal approach, the TEP approach eliminates the complications related to violation of peritoneal layer to reach the preperitoneal space. The need to close the peritoneal flap with tacks or sutures (in TAPP approach) also increases the operative time and cost.

We did open extra-peritonial mesh placement with satisfactory result. Genetic analysis was not possible in our institution [17].

\section{Conclusion}

Small size spigelian hernia poses diagnostic dilemma for clinicians. Diagnosis is easy if they are painful due to strangulation. Operation is treatment of choice. Hernias can also be treated laparoscopically (intraperitoneal or extraperitoneal approach) also.

\section{References}

[1] Spinelli, C., Palombo, C., Strambi, S., Pucci, V., Liserre, J. and Spinelli, G. (2013) Spigelian Hernia in a 14-Year-Old 
Girl: A Case Report and Review of the Literature. European Journal of Pediatric Surgery Reports, 2, 058-062. http://dx.doi.org/10.1055/s-0034-1370771

[2] Reinke, C. and Resnick, A. (2010) Incarcerated Appendix in a Spigelian Hernia. Journal of Surgical Case Reports, 2010, 3.

[3] Sarkar, P.G. (2013) Spigelian Hernia-A Rare Hernia, a Case in a Rare Site. International Journal of Pharma and Bio Sciences, 4, (B) 894-898.

[4] Sandalaski, P.N., et al. (2006) Spigelian Hernia: Surgical Anatomy, Embryology and Technique of Repair. Annals of Surgery, 72, 42-48.

[5] Rashid, F., et al. (2009) Atypical Right Diaphragmatic Hernia (Hernia Ofmorgagni), Spigelian Hernia and Epigastric Hernia in Apatientwith Williams Syndrome: Case Report. Journal of Medical Case Reports, 3, 7. http://dx.doi.org/10.1186/1752-1947-3-7

[6] Rushfeldt, C., et al. (2010) Spigelian Cryptorhidism Syndrome a Case Report and Discussion on the Basic Elements in a Possibly New Congenital Syndrome. Pediatric Surgery International, 26, 939-942. http://dx.doi.org/10.1007/s00383-010-2681-7

[7] Dabbas, N., et al. (2011) Frequency of Abdominal Wall Hernias: Is Classical Teaching out of Date? Journal of the Royal Society of Medicine, Short Paper, 2, 5.

[8] Rahman, J.M., et al. (2000) A Case of Spigelian Hernia at an Unusually High Anatomical Location. Journal of the Royal College of Surgeons of Edinburgh, 45, 196-197.

[9] Rogers, F.B. and Camp, P.C. (2001) A Strangulated Spigelian Hernia Mimicking Diverticulitis. Hernia, 5, 51-52. http://dx.doi.org/10.1007/BF01576167

[10] Campos, S.M. and Walden, T. (1997) Images in Clinical Medicine: Spigelian Hernia. The New England Journal of Medicine, 336, 1149. http://dx.doi.org/10.1056/NEJM199704173361605

[11] Carter, J.E. and Mizes, C. (1992) Laparoscopic Diagnosis and Repair of Spigelian Hernia: Report of Case and Technique. American Journal of Obstetrics \& Gynecology, 167, 77-78. http://dx.doi.org/10.1016/S0002-9378(11)91630-5

[12] Chowbey, P.K., Sharma, A., Khullar, R., Baijal, M. and Vashistha, A. (2000) Laparoscopic Ventral Hernia Repair. Journal of Laparoendoscopic \& Advanced Surgical Techniques, 10, 79-84. http://dx.doi.org/10.1089/lap.2000.10.79

[13] Gedeban, T.M. and Neubauer, W. (1998) Laparoscopic Repair of Bilateral Spigelian and Inguinal Hernias. Surgical Endoscopy, 12, 1424-1425. http://dx.doi.org/10.1007/s004649900873

[14] Kasiranjan, K., Lopez, J. and Lopez, R. (1997) Laparoscopic Technique in the Management of Spigelian Hernia. Journal of Laparoendoscopic \& Advanced Surgical Techniques, 7, 385-388. http://dx.doi.org/10.1089/lap.1997.7.385

[15] Moreno-Egea, A., Carrrasco, L., Girela, E., Martin, J.G., Aguayo, J.L. and Canteras, M. (2002) Open vs Laparoscopic Repair of Spigelian Hernia: A Prospective Randomized Trial. Archives of Surgery, 137, 1266-1268. http://dx.doi.org/10.1001/archsurg.137.11.1266

[16] Tarnoff, M., Rosen, M. and Brody, F. (2002) Planned Totally Extraperitoneal Laparoscopic Spigelian Hernia Repair. Surgical Endoscopy and Other Interventional Techniques, 16, 359. http://dx.doi.org/10.1007/s00464-001-4126-9

[17] Mittal, T., Kumar, V., Khullar, R., Sharma, A., Soni, V., Baijal, M. and Chowbey, P.K. (2008) Diagnosis and Management of Spigelian Hernia: A Review Literature and Our Experience. Journal of Minimal Access Surgery, 4, 95-98. http://dx.doi.org/10.4103/0972-9941.45204 